DOI 10.37882/2223-2982.2021.05-3.01

\title{
МЕТОДИЧЕСКАЯ ОБРАБОТКА АУТЕНТИЧНЫХ УЧЕБНЫХ МАТЕРИАЛОВ ПО ЯЗЫКУ СПЕЦИАЛЬНОСТИ ДЛЯ ИНОСТРАННЫХ ВОЕННОСЛУЖАЩИХ
}

\section{METHODOLOGICAL PROCESSING OF AUTHENTIC EDUCATIONAL MATERIALS ON THE LANGUAGE OF THE SPECIALTY FOR FOREIGN MILITARY PERSONNEL}

\section{Aseykina}

L. Kashina

Summary: The article is devoted to the problem of methodological processing (adaptation) of authentic educational materials in order to ensure their availability in the training of foreign military personnel. The methods of adaptation of the materials of the textbook on the language of the specialty developed at the department and the conditions for ensuring the effectiveness of the adapted materials for the formation of the communicative competence of students in the educational and professional sphere are considered. For the experimental verification, the parameters of methodological authenticity and criteria of the level of proficiency of foreigners in the Russian language in the framework of professionally-oriented training were used.

Keywords: authentic materials, methodological processing, specialty language, adaptation, foreign military personnel.

\author{
Асейкина Лариса Степановна \\ К.п.н., доцент, Краснодарское высшее военное \\ авиачионное училище летчиков \\ l.aseykina@gmail.com \\ Кашина Лариса Георгиевна \\ старший преподаватель, Краснодарское высшее военное \\ авиачионное училище летчиков
}

Аннотация: Статья посвящена проблеме методической обработки (адаптации) аутентичных учебных материалов в целях обеспечения их доступности при обучении иностранных военнослужащих. Рассмотрены способы адаптации разработанных на кафедре материалов учебного пособия по языку специальности и условия обеспечения эффективности адаптированных материалов для формирования коммуникативной компетенции обучающихся в учебно-профессиональной сфере. Для экспериментальной проверки использованы параметры методической аутентичности и критерии уровня владения иностранцами русским языком в рамках профессионально-ориентированного обучения.

Ключевые слова: аутентичные материалы, методическая обработка, язык специальности, адаптация, иностранные военнослужащие. $\mathrm{y}$ спешность профессионального обучения иностранных военнослужащих (ИВС) в авиационнотехническом вузе зависит от уровня коммуникативной компетенции, обеспечивающей «способность к обучению военной специальности на русском языке, развитию коммуникативных способностей (ВПК.ОК-3)», к участию ИВС в авиационном дискурсе. В коммуникативном пространстве дискурса формируется «профессиональная культура авиатора, в которой язык и мышление обусловлены технологией и объективной логикой профессиональной деятельности» [5, с. 42].

Коммуникативная компетенция ИВС формируется главным образом при изучении дисциплины «Язык специальности» с использованием аутентичных материалов. Понятие «аутентичные материалы» в методической науке не имеет четкого определения, хотя значение лексемы «аутентичный» - «подлинный, исходящий из первоисточника» [15, с. 63]. Аутентичными мы считаем материалы в текстовом, видео- $и$ аудио- формате, а также в виде иллюстраций и схем, взятые из оригинальных ис- точников и применяемые при обучении русскому языку как иностранному (РКИ).

В научно-методической литературе существуют различные подходы к описанию и анализу аспектов аутентичности: от определения самого понятия и свойств текста до характеристики учебного процесса $[4 ; 7 ; 8 ; 13]$. С позиций лингводидактики и методики преподавания аутентичность рассматривается как "соответствие содержательных, организационных и индивидуальных аспектов обучения иностранному языку естественному способу его функционирования в социуме» [4, с. 52]. «Каждый элемент урока - тексты, учебные задания, обстановка на занятии, учебное взаимодействие могут быть аутентичными. Задача преподавателя - добиться сочетания всех параметров аутентичности» $[14$, с. 130].

В профессионально-ориентированном обучении иностранному языку методисты выделяют функции аутентичных материалов: информационную, иллюстративно-наглядную, моделирующую, развивающую, ин- 
тегративную, креативную, мотивационную [13]. Через предметно-фактическую и событийную информацию аутентичные материалы демонстрируют языковую культуру представителей определённой профессии: образцы речи, элементы и формулы языка специальности, которые способствуют моделированию ситуаций профессионально-делового общения, формированию творческого мышления учащихся, готовность к поиску решения профессиональных проблем, а также к саморазвитию. Использование аутентичных материалов, считают А.А. Евтюгина, Н.А. Гриднева, М.А. Казакова, Н.В. Сидакова, Л.Е. Смирнова и другие, является эффективным способом формирования коммуникативной компетенции.

На практике, особенно в начальный период обучения, сложность аутентичных материалов приводит к нарушению важного принципа - языковой и смысловой доступности, поэтому их использование не всегда соответствует условиям и задачам обучения. Исследователи [4; 7; 10] отмечают факторы, вызывающие затруднения (различие культур, ментальные особенности, уровень базовых языковых знаний и речевых умений обучающихся и др.), и предлагают способы решения этой актуальной проблемы. В контексте обучения ИВС принцип доступности предполагает выполнение ряда требований, среди которых учет уровня исходной образовательной подготовки, приведение изучаемого материала в соответствие с познавательными способностями учащихся [16]. Н.А. Гриднева и другие методисты правомерно считают, что снять трудности в работе с аутентичными материалами можно только в учебном процессе, обучая учащихся с помощью индивидуальных методов «специальным стратегиям и тактикам работы с аутентичными материалами» [3, с. 211], формируя соответствующие умения и навыки.

Для решения проблемы доступности предлагается «оперативное изменение дидактических материалов с учетом специфики характеристик обучающихся» [16, с. 12], в частности, методическую обработку (адаптацию) аутентичных учебных материалов [9]. Анализ научнометодической литературы в этом аспекте показал недостаточную разработанность вопросов дифференциации обучения иностранных военнослужащих, адаптации учебных материалов по языку специальности, отсутствие практических рекомендаций в обеспечении их доступности, что, несомненно, влияет на достижение желаемых результатов в обучении иностранцев РКИ.

Цель данной статьи - исследовать способы методической обработки аутентичных материалов по языку специальности для формирования коммуникативной компетенции определенных групп ИВС. В задачи исследования входит: рассмотрение понятия «методическая аутентичность»; представление способов методической обработки специальных текстов и заданий к ним в соот- ветствии с параметрами методической аутентичности; оценка эффективности адаптированных материалов для первого курса по результатам их апробации в учебном процессе.

Научная новизна проведенного исследования состоит в представлении способов адаптации специальных учебных материалов и в обосновании условий, обеспечивающих их эффективность для формирования у определенных групп ИВС учебно-профессиональной коммуникативной компетенции.

В профессиональном обучении взаимодействуют разные источники информации (лекции преподавателей, учебные пособия, общение со специалистами, материалы СМИ, ресурсы сети Интернет, справочники и т.д.), интегрируя дисциплину «Язык специальности» В процесс военно-профессиональной подготовки ИВС, в которой коммуникативная компетенция обеспечивает возможность осуществлять учебную и служебную деятельность, теоретически и практически решать профессиональные задачи.

Одним из средств формирования коммуникативной компетенции ИВС являются разработанные нами дидактические материалы учебного пособия. Они отвечают задачам обучения, нормам, принятым в учебно-профессиональном дискурсе авиационных специалистов. Модули рабочей программы дисциплины коррелируют с программами спецпредметов, что предусматривало соответствующий отбор, организацию и экспертизу учебных материалов. Пособие содержит специальные тексты и функционально связанные с ними иллюстративные материалы и задания, с помощью которых изучается авиационно-техническая термосистема, многообразие логико-семантических связей понятий, содержание и структурная организация текстов, насыщенных актуальной профессиональной информацией. В целом учебные материалы пособия соответствуют критериям аутентичности: имеют тематическое единство, логическую целостность, естественность лексического наполнения и грамматических форм, адекватность в употреблении языковых средств [9]. Работа с материалами пособия приближает ИВС к реальным условиям использования русского языка в учебно-профессиональной сфере, развивает у них профессиональное мышление и сознание, повышает мотивацию ИВС к изучению специальности, совершенствованию языковых навыков.

Личностно-деятельностный подход к созданию и использованию учебных материалов пособия, принцип доступности диктуют их субъектно-ориентированную организацию и освоение, исходя из особенностей и интересов ИВС. Корректная адаптация аутентичных материалов сочетает «естественную коммуникацию и методическую эффективность», сохраняет «основные 
свойства аутентичных произведений с поправкой на конкретные задачи обучения и языковой уровень учащихся» [8, с. 28]. По сути, адаптация учебных материалов - это не упрощение, а «настройка» их на другого адресата, иную ситуацию общения, когда имеющиеся языковые средства не приводят к пониманию общих смыслов или тормозят их восприятие и надо искать новые способы коммуникации.

Опыт создания учебных пособий и работа с ними убеждают в том, что методическая обработка аутентичных материалов учебного пособия по языку специальности будет эффективна при следующих условиях: материалы должны адаптироваться на основе принципов научности и доступности, соответствовать параметрам методической аутентичности, а их освоение обеспечит оптимальный результат в формировании у ИВС учебнопрофессиональной коммуникативной компетенции.

Сложность адаптации заключается в том, что материалы пособия содержат учебно-познавательные единицы, введение которых предусмотрено учебной программой и необходимостью освоения, всей логикой языкового сопровождения спецдисциплин. Поэтому любые изменения материалов по устранению причин трудностей работы с ними следует производить осторожно и корректно, исходя из задач изучения дисциплины, в соответствии с «принципами научности и необходимой достаточности в представлении, квалификации и характеристике изучаемых языковых явлений» [6, с. 97], а также в интерпретации текстов. Адаптированные материалы будут понятны, а значит, эффективны, если опираются на языковое сознание обучающегося, его языковую картину мира, учитывают «особенности адресата, недостаток его знаний ...» $[11$, с. 68].

Основная цель адаптации текста - донести до обучающегося профессиональную информацию, «придать тексту собственную (индивидуальную) словесную форму мысли» (1, с. 5), сделать непонятные единицы языка и речевые модели понятными. Условием существования специального текста являются сильные элементы его структуры, обеспечивающие ему логическую связность: термины и профессионализмы, типовые синтаксические конструкции, значимые новые слова и сама информация. Они предстают как «система единиц, вербализующих некое когнитивное пространство - объединение концептов и категорий, связи между которыми носят взаимообусловленный характер» [11, с. 116].

Под адаптированным текстом мы понимаем «вторичный текст, измененный в содержательном и/или формальном отношении, построенный с учетом фоновых знаний и запросов потенциальных читателей, которые не могут понять текст-источник» [11, с. 59]. В процессе адаптации воссоздается необходимая для понимания референтной ситуации система знаний - вторичный текст, который «продуцируется на основе текста-источника, связан с ним содержательно-когнитивно» [11, с. 116], следовательно, сохраняет его понятийный аппарат.

Любой элемент структуры первичного текста, по мнению исследователей $[1,11]$, может быть адаптирован по принципу замены/незамены, где всякая замена предполагает оппозицию процессов исключения и дополнения элементов текста для его адекватного восприятия. Слабая функциональная нагрузка элементов структуры текста как раз и создает ситуацию замены. При методической обработке использовалась комбинация нелингвистических приемов (цитация, исключение, перестановка), связанных с изменениями композиции и структуры текста, и лингвистических (замена, редукция, добавление, инверсия), затрагивающих сферу языка. Эти приемы применялись как в совокупности, так и изолированно в соответствии с параметрами методической аутентичности.

Среди нелингвистических приемов адаптации специального текста доминирует цитация. Это дословное сохранение первичного текста по причине значимости текстовых компонентов по отношению к смысловой доминанте специального текста и/или соответствия уровню языковой и экстралингвистической подготовленности адресата. Прием исключения (изъятие части первичного текста) может быть связан с профессиональным интересом адресата (в нашем случае - летной или технической специализацией), устранением деталей в информации. Для курсантов-техников менее актуальны проблемы больших перегрузок, малозначимы дополнительные детали в описании условий полета.

\begin{tabular}{l|l} 
Кислородное оборудование (Ко) и снаря- & Кислородное оборудование \\
жение летчика обеспечивают создание & (КО) и снаряжение летчика \\
необходимых жизненных условий лёт- & обеспечивают ему необходи- \\
чику, сохранение его работоспособности & мые условия при выполнении \\
при выполнении высотных полётов, & высотных полётов и ката- \\
полётов сбольшими перегрузками и при \\
$\begin{array}{l}\text { катапультировании. } \\
\text { пультировании. }\end{array}$
\end{tabular}

Прием исключения позволяет упростить структуру всего текста о КО, выстроить четкую и динамичную линию в его описании, повысить внимание и степень заинтересованности адресата. При значительном или частичном исключении фрагментов текста используется прием перестановки, т.е. композиционное изменение текста оригинала ради упрощения формы предъявления информации. Исключение деталей, которые характеризуют состав и режимы функциональности частей КО, привели к уменьшению объема информации абзацев до самых значимых характеристик: назначения и размеще- 
ния КО. Иногда изменяется структурное членение всего текста, если исключаются целые абзацы, содержащие избыточную информацию, которая отвлекает от главного в изучении спецтекста - терминологии. Например, в адаптированном тексте о дистанционных приборах на базе терминологии дается описание приборов, их состав, принцип работы и не включена информация о причинах и особенностях размещения этих приборов на самолете.

Оппозицией исключения является прием добавления необходимых пояснений, комментариев, уточнений текстовой информации, которые включаются в текст: «...авиапушки имеют калибр (внутренний диаметр ствола)...», «...определять угол пеленга (направления)...» и др. Пояснения понятий, не включенные в текст, расширяют диапазон послетекстовых заданий, помогают создавать новые речевые ситуации.
Текст (фрагмент).

Вся информация о полёте, работе оборудования самолёта, действиях экипажа записывается системой объективного контроля. Расшифровка «чёрного ящика» проводится специалистами на земле.

\begin{abstract}
Задание 6. Прочитайте микротекст и расскажите о назначении и характеристиках устройства. «Чёрный ящик» - это бортовое устройство, которое записывает все параметры полёта. Оно имеет форму шара или цилиндра оранжевого ивета, жаро- и ударопрочный герметичный корпус.
\end{abstract}

Многокомпонентным лингвистическим приемом адаптации является редукция текста. В некоем синтезе сочетаются элементы разных приемов адаптации: исключения, добавления, замены, инверсии (перестановки) и цитации. Редуцированный фрагмент имеет относительную смысловую целостность, выступает как завершенный фрагмент, микротекст. При адаптации «сохраняется содержательно-смысловая основа микротекста, а утрачиваются только периферийные, несущественные для реципиента части смысла» [2, с. 111]. Опускаются или заменяются отдельные элементы грамматической структуры, и для вторичного текста выбираются единицы языка, наиболее частотные или упрощающие понимание смысла. Предпочитаются краткие причастия в типовых синтаксических конструкциях, простые предложения вместо сложноподчиненных, большинство глагольных перифраз заменяется однословным эквивалентом - глаголом (проводить испытания - испытывать, оказывать влияние - влиять).

В адаптированном фрагменте текста о радиосвязном оборудовании нет второстепенных деталей в описании речевых информаторов: когда они работают, какие рекомендации выдают. Ради упрощения восприятия смысла и сокращения объема высказывания произведены языковые замены в конструкциях (глагольно-именной и пассивной), использованы синонимия, инверсия.
Речевые информаторы (РИ) сообщают экипажу об аварийных ситуациях и опасных режимах в полёте, а также выдают рекомендации для принятия правильного решения. Для записи звуков используется магнитофон самолётный (MC).

Проведена методическая обработка всей системы текстовых заданий/упражнений в количественном и качественном отношении. Задания являются структурной единицей организации учебного материала, указанием преподавателя для учебных действий обучаемого, а упражнения обеспечивают выполнение этих действий [6]. Задания содержат рецептивные и репродуктивные упражнения для работы с готовым текстом, а продуктивные - целесообразно предлагать ИВС на старших курсах и в сильных языковых группах.

Пред-, при- и послетекстовые задания отражают «современную тенденцию к обучению аутентичному языку на аутентичном материале» [9, с. 23], связаны с лексико-грамматической структурой текстов на уровне слов, словосочетаний и предложений. При адаптации заданий сохранено их основное назначение и функциональная аутентичность, и лишь с конкретными языковыми единицами в определенном контексте проведена редукция.

Для облегчения и ускорения понимания предметной лексики максимально использованы изображения (рисунки, фотографии, схемы, таблицы). Некоторые термины и профессионализмы объясняются непосредственно в тексте с позиций их назначения и/или применения, другие понятия изучаются в предтекстовых заданиях через их толкование и системные связи. Редукция формулировок толкований проводится на базе известной обучающимся лексике при исключении деталей и синтаксического усложнения, замене труднопроизносимых слов с нетерминологическим значением (например, причастий). Адаптированный вариант толкования должен обладать относительной целостностью, выступать как завершенный фрагмент, микротекст, сохраняющий смысловое ядро определения.

Устройство - это рукотворный
объект (прибор, механизм, кон-
струкция, установка, аппарат,
машина) со сложной внутренней
структурой, созданный для вы-
полнения определённых функций,
обычно в области техники.
Устройство - это прибор, механизм, конструкция, установка, аппарат, машина, которые используются в технике.

Упражнения насыщены элементами профессионального дискурса. 
Существование интернациональных аналогов русских слов в техническом языке может быть положительным фактором для одних иностранцев и осложнять обучение других, не владеющих европейскими языками. Одинаково важным для всех является использование аббревиатур, помогающих до минимума сократить языковые средства, время и речевые усилия ИВС, при этом сохраняется понимание терминологии и облегчается восприятие текста. Для отработки синтаксических конструкций из многих вариантов выбираются наиболее частотные в дискурсе.

При выполнении заданий предусматривается педагогическое сопровождение. Предлагаются модели (образцы) трансформаций структуры предложений-высказываний; слова или словосочетания-опоры для построения предложений и микротекстов; «слова для справок», содержащие варианты для выбора (объяснения значений слов, аббревиатуры, синонимы, купированные фрагменты текста и профессиональных диалогов и т.д.); в формулировках вопросов к тексту минимизируется перефразирование. Задания нацеливают ИВС на естественность и креативность в выборе языковых средств для решения определенной лингвистической задачи в учебно-профессиональной сфере, организуют повтор отрабатываемого речевого действия, формируют у иностранцев «автоматизм трансформаций, осознанность в восприятии лексико-грамматического материала с учетом особенностей социального контекста» [6, с. 97].

Итак, данное исследование методической обработки аутентичных учебных материалов проведено в соответствии с условиями достижения их практической эффективности для начального обучения языку специальности определенных групп ИВС. Результатом адаптации являются количественные и качественные изменения. Статистический анализ текстов показал: средний объем адаптированных текстов - 90 слов вместо 150; количество предложений - 9 вместо 11; длина предложений 10 слов вместо 14. Стандартный урок учебного пособия содержит 15-18 заданий, а в адаптированном материале - 9-12 с меньшим числом языковых единиц.

Личностно-деятельностный подход к адаптации и соблюдение принципов научности и доступности позволяют обеспечить сохранение информационного ядра и понятийного аппарата специальных текстов и снять трудности в освоении ИВС учебных материалов. Функционально-коммуникативный подход к использованию адаптированных материалов нацеливает на выполнение задач изучения дисциплины, формирование у ИВС учебно-профессиональной коммуникативной компетенции.

Адаптированные тексты аутентичны структурно, т.е. логично выстроены информативные элементы текстовописаний (определения понятий, состав, характеристи- ки и назначение оборудования), которые обеспечивают текстам содержательную и формальную целостность. Причинно-следственные, условные, модальные и др. отношения между элементами текстов создают логикограмматическую связность. Исключение из вторичных текстов деталей, избыточной информации не коснулось заявленной содержательно-когнитивной основы.

Лексическая аутентичность адаптированных материалов обеспечивается сохранением терминологического наполнения и допустимых в тексте 5\% незнакомых лексических единиц для изучающего чтения [7]. Грамматическая аутентичность оформления предложений связана с использованием в устной и письменной речи характерных для специальных текстов грамматических структур. Ориентация адаптированных материалов на языковые особенности спецтекстов и нормы профессионального дискурса делает их функционально аутентичными, приближает ИВС к реальным условиям употребления языка, готовит к самостоятельному выбору языковых средств для участия в учебно-профессиональном дискурсе.

Экспериментальная проверка эффективности адаптированных учебных материалов опиралась на существующие «критерии уровня владения ИВС русским языком в рамках профессионально-ориентированного обучения»: владение языком профессии, готовность к речевому профессиональному взаимодействию и творческой деятельности [5, с. 255].

Сравнительный анализ успеваемости (текущий, рубежный контроль) 1-й группы курсантов, работавшей с адаптированными материалами, и 2-й группы, которая на первом курсе использовала учебное пособие, показал повышение на 23\% уровня знаний научных терминов и профессионализмов, навыков адекватного использования речевых моделей и конструкций, типичных для авиационно-технической речи. По итогам сессии и учебной практики средний балл в 1 -ой группе $(3,8)$ оказался выше, чем во 2-ой $(2,7)$.

Опрос (анкетирование) курсантов выявил уровень понимания спецтекстов, возможность функционального использования изученных языковых единиц на занятиях и в работе со специалистами, эффективность педагогической помощи при выполнении заданий. Курсанты заявили о востребованности адаптированных материалов, помогающих систематизировать первичные знания по спецпредметам, логично строить высказывание, вести учебно-профессиональный диалог.

Наблюдения за проявлениями активности и самостоятельности курсантов в учебной и внеучебной сфере показали, что освоение понятного учебного материала усиливает мотивацию к обучению, стимулирует познавательную и творческую активность в поиске про- 
фессиональной информации, чтении дополнительной литературы, в беседах с преподавателями. Курсанты демонстрировали предметную компетентность, умения решать коммуникативные и профессиональные задачи разной сложности.

Надежность и достоверность полученных экспериментальных данных обеспечена соблюдением условий нашего исследования и подтверждена проверкой контролируемых факторов методами математической статистики [12].

Представленные в статье способы методической обработки могут быть полезны в практике дифференцированного обучения иностранных учащихся, когда адаптация аутентичных учебно-профессиональных ма- териалов будет действенным средством в решении задач обучения языку специальности. Доказано, что достижение эффективности этих материалов возможно на базе заявленных методологических подходов к их адаптации и освоению, при соблюдении принципов научности и доступности, соответствия адаптированных материалов критериям методической аутентичности.

Творчески подходя к проектированию и реализации учебных задач, учитывая условия работы с конкретной группой иностранных учащихся, уровень их языковой подготовки, профессиональные интересы и потребности, преподаватели могут методически обрабатывать аутентичные учебные материалы, обеспечивая им нужный уровень сложности.

\section{ЛИТЕРАТУРА}

1. Брыгина А.В. Лингвистические принципы адаптирования художественного текста. Автореферат дисс. ... канд. филол. наук: 10.02.01. М., 2005. 20 с.

2. Брыгина А.В. 0 некоторых особенностях редукции как лигвистического приема адаптирования // Вестник Московского университета. Серия 19. Лингвистика и межкультурная коммуникация. 2011. № 4. С. 108-115.

3. Гриднева Н.А. Использование аутентичных материалов в обучении иностранному языку на уровне А1 // Самарский научный вестник. 2017. Т.6, № 4(21). C. 210-214.

4. Казакова М.А., Евтюгина А.А. Аутентичные текстовые материалы в обучении иностранному языку // Вестник Бурятского гос. университета. Образование. Личность. 0бщество. 2016. Вып. 4. С. 50-60.

5. Казачкова М.Б. Профессиональный язык как отражение профессиональной культуры: Монография. М: «0ргсервис - 2000», 0динцово, 2010. 112с.

6. Кондрашова 0.В., Шельдешова И.В. Сочетание текстовых упражнений в учебных пособиях по иностранному (русскому) языку для курсантов авиационных специальностей. // Актуальные проблемы теоретической и прикладной лингвистики. Материалы VI Всероссийской научно-практической конференции. 16-17 июля 2020 года. - Краснодар: Краснодарское ВВАУЛ, 2020. С. 91-102.

7. Мирошникова Е.А. Адаптация текстового учебного материала при дифференцированном обучении иностранному языку. // Вестник Брянского госуниверситета, 2016(3). С.229-234.

8. Носонович Е.В. Методическая аутентичность учебного текста: дисс. ... канд. пед. наук: 13.00.02 / Е.В. Носонович. М.: РГБ, 2003. 178 с.

9. Носонович Е.В., Мильруд Р.П. Параметры аутентичного учебного текста // Иностранные языки в школе. - 1999. - № 1. - С.18-23.

10. Первухина С.В. Когнитивно-семантическая связь вторичных текстов и их текстов-источников // Вестник Ленинград. гос. ун-та им. А.С. Пушкина. Т. 1. Филология. № 2. СПб., 2012. С. 116-125.

11. Первухина С.В. Структура, семантика и прагматика адаптированного текста: диссертация ... доктора филолог. наук: 10.02.19. - Ставрополь, 2016. 302 с.

12. Селютин В.Д. Экспериментальная проверка влияния контролируемых факторов в педагогике // Современные проблемы физико-математических наук. Материалы III Международной научно-практической конференции, 23-26 ноября 2017 г. / под общ. ред. Т.Н. Можаровой. 0рел: 0ГУ, 2017. С. $529-534$.

13. Сидакова Н.В. Использование профессионально-ориентированных аутентичных материалов в обучении иностранному языку студентов технических специальностей. АНИ: педагогика и психология. 2016. Т.5. № 3(16). С. 154-157.

14. Смирнова Л.Е. Методическая аутентичность в обучении иностранному языку // Инновационная наука. 2016. № 11-2. С. 129-131.

15. Современный словарь иностранных слов. М.: Русский язык, 2001. 742 с.

16. Тенитилов П.С. Обучение иностранных военнослужащих на основе принципа доступности. Автореферат дисс. ... канд. пед. наук: 13.00.08. М., 2018. 24 с. 